\title{
Treatment of gastrocolic fistula with home total parenteral nutrition: Report of a case and review of the literature
}

\author{
STANLEY D. KOLMAN, D.O., FACOS \\ ANTHONY A. MINISSALE, D.O., FACOS \\ VIVIAN M. BARSKY, D.O., FACOS \\ Philadelphia, Pennsylvania
}

The paper presented here reviews a case of benign gastrocolic fistula which was treated conservatively with home parenteral nutrition. The literature is reviewed, and a scheme of management is presented.

Before Dudrick's work with total parenteral nutrition (TPN) in 1968, the mortality rate for patients with gastrointestinal tract fistula was $30-50$ percent. ${ }^{1}$ The principal causes of death in the historic sense were malnutrition, electrolyte imbalance, and sepsis. Surprisingly, mortality did not decrease during the "hyperalimentation period," even though rates of spontaneous closure of the fistula increased. ${ }^{1}$ The treatment of choice at that time was early resection of the involved portion of bowel along with the fistulous tract.

There has been a marked improvement in mortality rate over the last 20 years, with the rate reported by Rose and associates ${ }^{2}$ in 1986 of 10.5 percent comparing favorably with other recent literature. Management of gastrointestinal tract fistulas has changed from a transient reliance on TPN when preparing a patient for operative intervention to expectation of closure utilizing nutritional support as a primary therapy. ${ }^{3}$ Although mortality rates have stabilized, spontaneous closure rates continue to increase. ${ }^{2}$ Several investigators have been able to double nonoperative closure rates with the appropriate use of TPN. ${ }^{4}$

In 1975 , Strang and coworkers ${ }^{5}$ reported that the spontaneous gastrocolic fistula arising from benign gastric ulcer was a rarity; their review of the liter- ature (1897-1973) revealed only 54 reported cases. This paper presents a case study of gastrocolic fistula secondary to recurrent peptic ulcer disease. The patient was treated with home total parenteral nutrition (HTPN), and spontaneous closure was achieved. To our knowledge, this is the first reported case of successful conservative treatment of benign gastrocolic fistula.

\section{Report of case}

A 32-year-old white man was admitted in 1979 with a 13-year history of recurrent duodenal ulcer disease. He had been treated with all of the available conservative methods of therapy; however, repeated endoscopy showed continued active ulceration. Gastric analysis results and serum gastrin levels were normal. The patient underwent uneventful pyloroplasty (Finney procedure) with truncal vagotomy. He was discharged on the ninth postoperative day without complication. An upper gastrointestinal series obtained a month after surgery essentially was unremarkable except for the surgical deformity.

The patient remained well until October 4,1981 , when he was admitted, when he developed abdominal bloating, belching, and progressive lethargy associated with weight loss. Physical findings on admission revealed tenderness in the upper right quadrant without signs of peritonitis. Barium enema examination was negative. The upper gastrointestinal films revealed a gastrocolic fistula (Fig. 1). Endoscopy showed a deformed pylorus, with no evidence of active ulceration. The patient decided that he did not wish to undergo further 

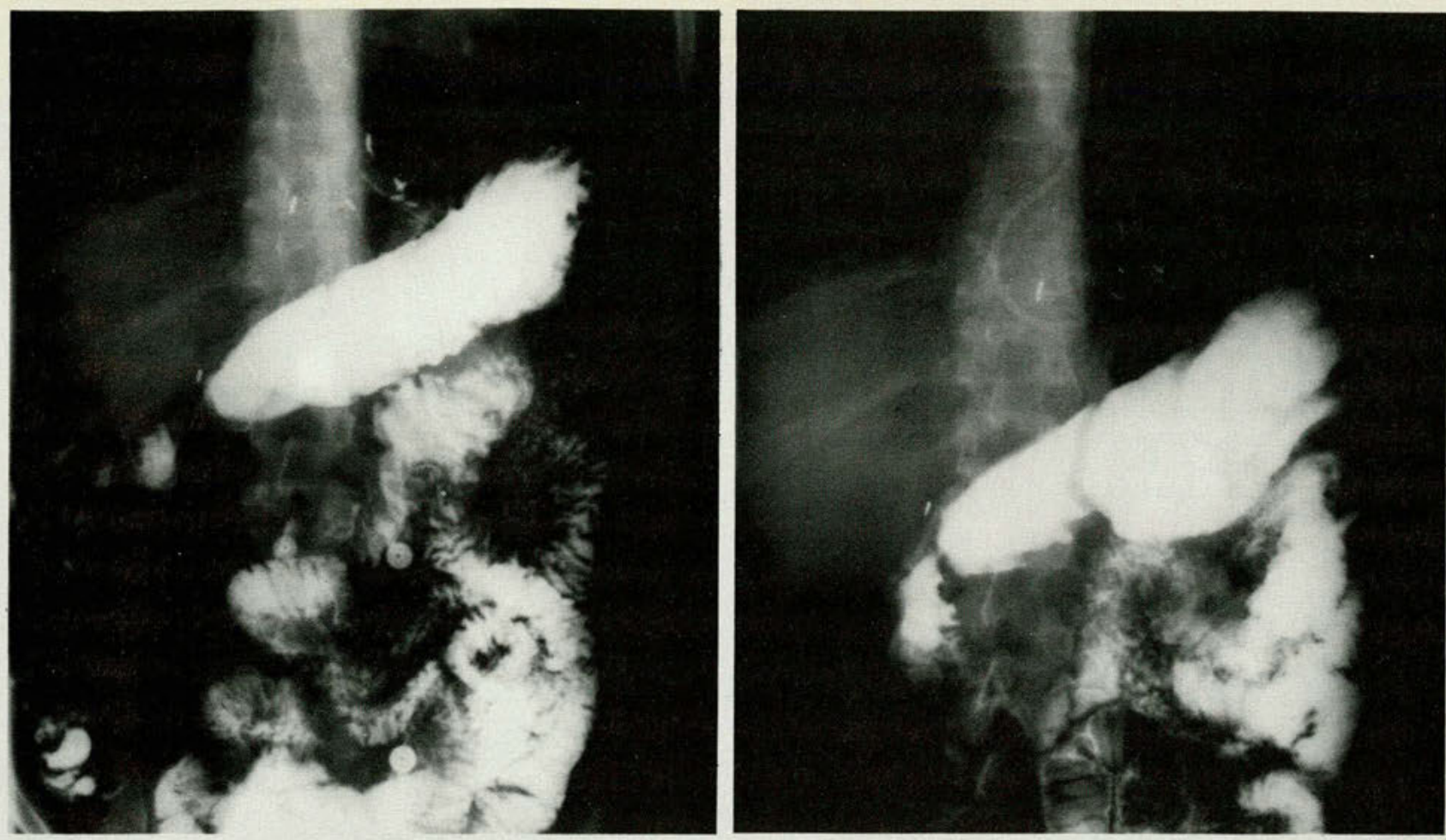

Fig. 1. Upper gastrointestinal film reveals gastrocolic fistula (prior to TPN therapy). Fig. 2. No evidence of gastrocolic fistula is seen on upper gastrointestinal film following 2 weeks of TPN, 6 weeks of HTPN, and 4 weeks of oral diet.

surgery because of business problems, and he was discharged on a regimen of antacids and Tagamet.

He was readmitted on October 29, 1981, and was placed on nothing-by-mouth status. TPN was begun with 3,092 calories, 24.4-29.6 gm. of nitrogen, and electrolytic and trace elements. Calorie requirements were determined by utilizing a multiple (1.76) of the basal energy expenditure, as calculated by the Harris-Benedict equations for male patients, that is, $66.5+13.78$ (weight in kg.) +5.03 (height in $\mathrm{cm}$.) -6.76 (age). Protein requirements were determined by measuring 24 -hour excretion of total urinary nitrogen (15.2-20.6 gm.), compensating for obligatory nitrogen loss (about 6 gm.), and adding 3 more grams to achieve positive nitrogen balance. The ratio of nonprotein calories to grams of nitrogen was maintained at $156: 1 .^{6}$

On November 10, a Hickmann catheter was placed and training for HTPN was started. The patient was discharged and his home therapy was instituted. Six weeks later, outpatient upper gastrointestinal radiography failed to demonstrate the gastrocolic fistula. An oral diet was begun, and the patient was weaned slowly from the HTPN regimen. A repeat upper gastrointestinal series 4 weeks later again failed to demonstrate the fistula (Fig. 2).

Table 1 lists the nutritional parameters followed during the course of therapy. It should be noted that throughout the course of therapy, albumin, transferrin, and anthropometric measurements remained stable or improved.

\section{Discussion}

The most common cause of gastrocolic fistula is carcinoma of the colon or stomach. According to Verbrugge,${ }^{7}$ the first report of such a lesion was in 1755 by Haller. The etiologies of gastrocolic fistula are listed in Table 2. The classic symptom triad of diarrhea, weight loss, and feculent vomiting or stercolic breath are noted in 90 percent of patients with a malignancy; patients with benign fistula have this complex in approximately 25 percent of cases. ${ }^{8}$ A summary of presenting symptoms is presented in Table $3 .^{8}$

Diagnosis of gastrocolic fistula is usually made with a barium enema $\mathrm{x}$-ray; the percent of effective diagnosis is quite high. The upper gastrointestinal series will show positive findings in $35-40$ percent of cases. Gastroscopy and colonoscopy are usually unreliable diagnostic tools in this clinical entity. ${ }^{8}$

Haffejee and authors ${ }^{9}$ in 1980 demonstrated that nutritional support obviates the need for early operative intervention in the treatment of patients with gastrointestinal tract fistula. This procedure has proved to be exceptionally useful for patients who are unable to undergo surgery. Table 4 presents the indications for operative intervention, as 
TABLE 1. NUTRITIONAL PARAMETERS DURING PATIENT'S THERAPY.

\begin{tabular}{|c|c|c|c|c|}
\hline \multirow[b]{2}{*}{ Parameter } & \multicolumn{4}{|c|}{ Measurement } \\
\hline & Initial & Week 1 & Week 4 & End \\
\hline $\begin{array}{l}\text { Total protein } \\
\text { (gm./dl.) }\end{array}$ & 6.1 & 6.1 & 6.3 & 6.6 \\
\hline Albumin & & & & \\
\hline (gm./dl.) & 4.0 & 4.2 & 4.4 & 4.4 \\
\hline $\begin{array}{l}\text { Total iron binding capacity } \\
\text { (mg. \%) }\end{array}$ & 291 & 243 & 309 & 300 \\
\hline $\begin{array}{l}\text { Lymphocyte count } \\
\text { (per cu. mm.) }\end{array}$ & 2,208 & 2,525 & 3,350 & 3,444 \\
\hline Transferrin (percent below normal range) & 12 & 12 & 12 & Normal \\
\hline $\begin{array}{l}\text { Mean midarm circumference } \\
\text { (percent below normal range) }\end{array}$ & 2.9 & 2.9 & 2.9 & Normal \\
\hline $\begin{array}{l}\text { Creatinine height index } \\
\text { (percent below normal range) }\end{array}$ & 6 & 6 & Normal & Normal \\
\hline Weight (kg.) & 60 & 62 & 62.5 & 64.5 \\
\hline $\begin{array}{l}\text { 24-hr. urinary nitrogen } \\
\text { excretion (gm.) }\end{array}$ & 15.2 & 15.4 & 18.5 & 20.6 \\
\hline $\begin{array}{l}\text { Protein requirements (gm.) } \\
\text { Adjusted basal energy }\end{array}$ & 24.2 & 24.4 & 27.5 & 29.6 \\
\hline expenditure (calories) & 3,092 & 3,092 & 3,092 & 3,092 \\
\hline Ideal body weight (kg.) & 63.8 & 63.8 & 63.8 & 63.8 \\
\hline
\end{tabular}

reported by Rose and associates. ${ }^{2}$ In the present era, mortality largely is caused by uncontrolled sepsis and sepsis-related malnutrition. In the presence of uncontrolled sepsis, malnutrition cannot be treated by TPN without effective drainage. When sepsis control is achieved, TPN will result in good nutritional status, thus allowing skin lesions to heal and the future surgical site to become quiescent. ${ }^{1}$ Rose and associates ${ }^{2}$ reported that 90 percent of patients with surgical control of sepsis subsequently had their fistula close spontaneously. Byrne and coworkers, ${ }^{10}$ in 1979 , reported the use of HTPN as an alternative approach to the management of gastrointestinal fistula. They were able to achieve a 66 percent overall closure rate (surgery and TPN), with a 50 percent spontaneous closure rate, in 12 patients who were treated with HTPN after conventional therapy failed.

A management protocol by Kashuk and Moore ${ }^{11}$ is presented in Figure 3. It should be noted that TPN is either supportive or used as preoperative preparation in this protocol. Biopsy is essential to determining whether the gastrocolic fistula is a result of benign or malignant disease. Biopsy specimens can be obtained at laparotomy (if surgery is emergent), or via gastroscopy if delay in surgical intervention is required..$^{10}$ If malignancy is found, more extensive resection may be needed to remove the fistulous tract.

A benign biopsy result may allow a more extensive trial of TPN to close the fistula, especially when considering our success in the case discussed here. Halasz ${ }^{3}$ noted that several conditions are necessary if TPN is to be successful as a primary treatment modality for gastrointestinal fistula. Distal

\begin{tabular}{|l|}
\hline TABLE 2. ETIOLOGIES OF GASTROCOLIC FISTULA. \\
\hline Colonic cancer \\
Gastric cancer \\
Recurrent peptic ulcer disease \\
Unoperated gastric ulcer disease \\
Inflammatory bowel disease \\
Syphilis \\
Intestinal tuberculosis \\
Colonic carcinoid \\
Trauma \\
Congenital abnormality \\
Colonic diverticulitis \\
Adenocarcinoma of pancreas \\
Radiation enteritis \\
Intraperitoneal abscess
\end{tabular}

\begin{tabular}{|lc|}
\hline \multicolumn{2}{|l|}{ TABLE 3. PRESENTING SIGNS AND SYMPTOMS OF GASTROCOLIC } \\
FISTULA. & ${ }^{8}$ \\
\hline Symptom & Percent of cases \\
\hline Pain & $70-90$ \\
Diarrhea & $70-80$ \\
Weight loss & $70-80$ \\
Fecal vomit & $30-80$ \\
Abdominal mass & Most often when cancer \\
& is present \\
\hline
\end{tabular}

TABLE 4. INDICATIONS FOR SURGICAL INTERVENTION IN 114 CASES OF TRACT FISTULA. ${ }^{2}$

\begin{tabular}{|lc|}
\hline Indication & No. of patients \\
\hline Abscess drainage & 23 \\
Abscess and distal obstruction & 1 \\
Epithelialization of tract & 8 \\
Distal obstruction & 7 \\
Inflammatory disease & 8 \\
Fistulous tract tumor & 3 \\
Sepsis & 3 \\
External diversion and control of sepsis & 3 \\
\hline
\end{tabular}

obstruction, carcinoma, granuloma, active infection, mucosal eversion, or a foreign body will reduce, or eliminate, the possibility of spontaneous closure. 


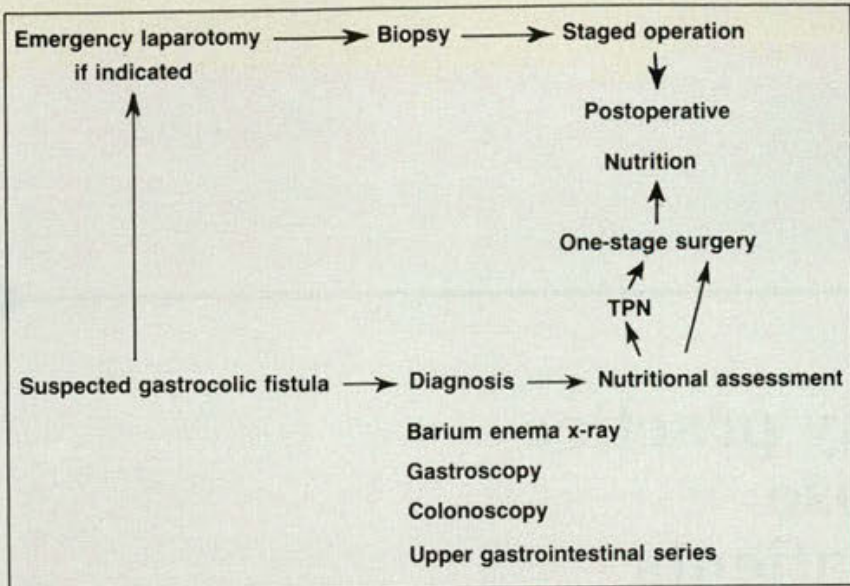

Fig. 3. Current management of gastrocolic fistula ( modified from Kashuk and Moore ${ }^{I 1}$.

The perpetuation of fistulous tracts is most probably caused by mucosa lining the entire tract and connecting to a functional portion of the intestinal tract. $^{3}$ The basic therapy for any gastrointestinal fistula is to delineate the fistulous tract, decrease the output of the fistula, manage resultant skin problems, correct nutritional deficits, and divert the gastrointestinal tract proximal to the fistula. Even patients without nutritional deficits prior to fistulization will have increased demands for calories and protein because of sepsis, loss of protein fluid, and loss of absorptive capacity. ${ }^{12}$

We chose HTPN as a primary therapy for our patient's gastrocolic fistula because of several interrelated factors: First, he was reluctant to undergo a surgical procedure; second, he fit the criteria set by Halasz $^{3}$ for the use of TPN as a primary treatment modality; and third, he had not reached the stage of fistula in which severe nutritional deficits were present. The patient's eager ability to be trained in the delivery of HTPN and his subsequent return to a near normal lifestyle during treatment were quite beneficial to the ultimate success of the therapy. The current literature is replete with documentation $^{13-16}$ of the safety of HTPN. The safe use of indwelling right atrial catheters has also been well documented. ${ }^{17-19}$

\section{Summary}

This article presents a case study of benign gastrocolic fistula secondary to recurrent peptic ulcer disease that was successfully treated nonoperatively with HTPN. The rarity of spontaneous closure in the treatment of gastrocolic fistula and the uncommoness of this clinical entity are documented. The literature pertaining to gastrointestinal fistula and the impact of TPN on treatment is reviewed. Alternative treatment protocols for gastrocolic fistula are discussed.

1. Soeters, P.B., Ebeid, A.M., and Fischer, J.E.: Review of 404 patients with gastrointestinal fistulas. Impact of total parenteral nutrition. Ann Surg 190:189-202, Aug 79

2. Rose, D., et al.: One hundred and fourteen fistulas of the gastrointestinal tract treated with total parenteral nutrition. Surg Gynecol Obstet 163:345-50, Oct 86

3. Halasz, N.A.: Changing patterns in the management of small bowel fistulas. Am J Surg 136:61-5, Jul 78

4. Thomas, R.J.S.: The response of patients with fistulas of gastrointestinal tract to parenteral nutrition. Surg Gynecol Obstet 153:77-80, Jul 81

5. Strang, G.I., et al.: Benign gastrocolic fistula healing with conservative management. Arch Surg 112:651-4, May 77

6. Rutten, P.R., et al.: Determination of optimal hyperalimentation infusion rate. J Surg Res 18:477-83, May 75

7. Verbrugge, J.: Gastrojejunocolic fistulas. Arch Surg 11:790-808, Nov 25 8. Morton, R.E., et al.: Gastrocolic fistula secondary to benign gastric ulcer not operated upon. Case report and review of the literature. South Med J 70:201-4, Feb 77

9. Haffejee, A.A., Angorn, I.B., and Baker, L.W.: Nutritional support in high-output fistulas of the alimentary tract. S Afr Med J 57:227-31, Feb 80

10. Byrne, W.J., et al:: Home parenteral nutrition. An alternative approach to the management of complicated gastrointestinal fistulas not responding to conventional medical or surgical therapy. JPEN 3:355-9, Sept-Oct 79

11. Kashuk, J.L., and Moore, E.E.: Gastrocolic fistula. A new look. Nutr Support Serv 1:25-6, Nov 81

12. Reber, H.A., et al.: Management of external gastrointestinal fistulas. Ann Surg 188:460-7, Oct 78

13. Byrne, W.J., et al.: Home parenteral nutrition. Surg Gynecol Obstet 149:593-9, Oct 79

14. Scribner, B.H., Riella, M., and Broviac, J.W.: The artificial gut. Four year's experience with total parenteral nutrition (TPN) in the home. International Congress of Parenteral Nutrition, Montpellier, N.Y., 1974 15. Jeejeebhoy, K.N., et al.: Total parenteral nutrition at home. Studies in patients surviving 4 months to 5 years. Gastroenterology 71:943-53, Dec 76

16. Dudrick, S.J., et al.: Ambulatory home parenteral nutrition. Ann Surg 199:770-81, Jun 84

17. Hickman, R.O., et al.: A modified right atrial catheter for access to the venous system in marrow transplant recipients. Surg Gynecol Obstet 148:871-5, Jun 79

18. Fleming, C.R., Witzke, D.J., and Beart, R.W., Jr.: Catheter-related complications in patients receiving home parenteral nutrition. Ann Surg 192:593-9, Nov 80

19. Steiger, E., ed.: Home parenteral nutrition. ASPEN Publications, Chicago and Baltimore, 1981

Dr. Kolman is attending surgeon and director, Nutrition Support Service, Metropolitan Hospital, Parkview Division, Philadelphia. Dr. Minissale is chairman, Department of Surgery, Parkview Divsion, where Dr. Barsky is cochairman.

Dr. Kolman, 1331-45 East Wyoming Avenue, Phildelphia, Pennsylvania 19124 . 